\title{
Biomarkers for Early Detection of Alzheimer Pathology
}

\author{
C.M. Clark ${ }^{a, d-f}$ C. Davatzikos ${ }^{b} \quad$ A. Borthakur ${ }^{b} \quad$ A. Newberg ${ }^{b} \quad$ S. Leight ${ }^{c, g}$ \\ V.M.-Y. Lee ${ }^{c, f, g} \quad$ J.Q. Trojanowski ${ }^{\mathrm{c}-\mathrm{g}}$ \\ Departments of ${ }^{a}$ Neurology, ${ }^{b}$ Radiology and ${ }^{\mathrm{c} P a t h o l o g y}$ and Laboratory Medicine, ${ }^{\mathrm{d}}$ Center of Excellence for \\ Research on Neurodegenerative Diseases, ${ }^{\mathrm{e}}$ Alzheimer Disease Center, ${ }^{\mathrm{f}}$ Institute on Aging, and ${ }^{\mathrm{g}}$ Center for \\ Neurodegenerative Disease Research, University of Pennsylvania, Philadelphia, Pa., USA
}

\section{Key Words}

Biomarkers • Alzheimer's disease $\cdot$ Diagnosis ·

Neurodegenerative disease

\begin{abstract}
The increasing prevalence of Alzheimer's disease and the devastating consequences of late-life dementia motivates the drive to develop diagnostic biomarkers to reliably identify the pathology associated with this disorder. Strategies to accomplish this include the detection of altered levels of tau and amyloid in cerebrospinal fluid, the use of structural MRI to identify disease-specific patterns of regional atrophy and MRI $T_{1} \rho$ to detect disease-related macromolecular protein aggregation, and the direct imaging of amyloid deposits using positron emission tomography and single photon emission computerized tomography. Success will facilitate the ability to reliably diagnose Alzheimer's disease while the symptoms of brain failure are mild and may provide objective measures of disease-modifying treatment efficacy.
\end{abstract}

Copyright $\odot 2008$ S. Karger AG, Basel

\section{Introduction}

The steadily increasing number of individuals at risk for late-life dementia and the promise of pathologically targeted disease-modifying therapy has made the devel- opment of methods to establish a reliable diagnosis of Alzheimer's disease (AD) at the earliest stage possible an important public health goal. Biologic markers to detect the presence of $\mathrm{AD}$ pathology represent one strategy to accomplish that goal. Developing and validating biomarkers capable of detecting the neurodegenerative changes associated with $\mathrm{AD}$ is a major aim of the clinical and laboratory neurodegenerative disease-focused programs at the University of Pennsylvania (PENN). Biomarkers based on the detection of pathologically linked proteins in spinal fluid, identification of neurodegenerative disease-associated regional brain atrophy, and the use of MRI to detect pathologic protein aggregation are helping to move the identification of $\mathrm{AD}$ from the traditional approach based on recognizing diagnostically related cognitive and behavioral phenotype to the more definitive and reliable detection of disease-specific pathology.

\section{Moving the Diagnosis from Identifying Signs and Symptoms of Cognitive Brain Failure to the Detection of Disease-Specific Pathology}

There are a variety of neurodegenerative pathologies associated with the development of late-life dementia, with an equally complex and evolving array of diagnostic labels. While AD is by far the most prevalent [1], cogni-

\section{KARGER \\ Fax +4161306 1234 E-Mail karger@karger.ch} www.karger.com

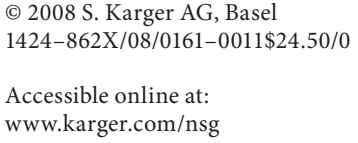

Chris M. Clark, MD

Penn - Ralston Center, University of Pennsylvania

3615 Chestnut Street

Philadelphia, PA 19104 (USA)

Tel. +1 215662 7810, Fax +1 215662 7812, E-Mail chris.clark@uphs.upenn.edu 
tive brain failure associated with a variety of frontotemporal lobar degenerations (for example Pick's disease, frontotemporal dementia with parkinsonism, frontotemporal dementia with motor neuron disease) and midbrain syndromes (such as Parkinson's dementia, progressive supranuclear palsy, corticobasal degeneration) are also associated with progressive dementia. Each has a recognizable pathological fingerprint. The clinical phenotype, and thus the clinical diagnostic criteria for each, is primarily based on the areas of the brain most affected during the initial stage of the illnesses. However, mixed pathologies are common, challenging the clinician's ability to identify the single or dominant pathology responsible for the patient's cognitive brain failure.

Laboratory-based methods to detect the earliest changes associated with these neurodegenerative pathologies and definitively identify the responsible pathology have the potential to increase diagnostic certainty, particularly during the initial stage of cognitive brain failure, and perhaps to provide information about disease activity that can be used to measure treatment efficacy [2].

$\mathrm{AD}$ is the major cause of late-life dementia in the United States, with an increasing personal, social and economically devastating burden associated with the steady growth of the number of individuals living into the eighth and ninth decade of life [3]. As a result, progress in the early and reliable identification of AD and the discovery of disease-modifying treatments have become major public health goals. Accomplishing both will require a shift from the traditional approach of detecting and diagnosing specific types of late-life neurodegenerative dementia based on the clinical phenotype of cognitive failure to one that includes the detection of the responsible pathology as part of the diagnostic inclusion criteria. The laboratory tools to accomplish this include biochemical methods (detection of pathological proteins in cerebrospinal fluid), imaging methods (detection of regional atrophy patterns on MRI and the identification of deposits of aggregated protein using MRI $T_{1} \rho$ ), and the use of positron emission tomography (PET) and single photon emission computerized tomography (SPECT) compatible radioactive ligands retained by the neuropathologic lesions to visualize the distribution and intensity of the lesions. These tools are collectively called biomarkers, as they use biologically based methods to 'mark' the presence of pathology.

There are several reasons for the emerging need to incorporate biomarkers into the diagnostic criteria used by clinicians to identify the dominant pathology (or mix of pathologies) responsible for a patient's cognitive failure. They include the increasing recognition that a variety of neurodegenerative and vascular pathologies can coexist, each capable of contributing to the symptomatic expression of cognitive brain failure. In addition, a single type of pathology can produce a variety of different types of cognitive and behavioral symptoms, making it difficult to reliably identify the pathology based solely on the clinical phenotype. And lastly, it is recognized that the pathological process begins decades before the first symptoms of brain failure, making early identification based on symptomatic cognitive failure difficult in a situation where the initiation of early treatment is imperative to achieve the maximum benefit from pathologically targeted disease-modifying drugs.

Developing the tools to accomplish this goal is the primary aim of the biomarkers of late-life dementia program at PENN. The focus is the identification of pathology associated with $\mathrm{AD}$.

Because it is unlikely a single biomarker will provide the diagnostic certainty needed by clinicians and patients, we have initiated a multimodality approach that incorporates biochemical methods, anatomic imaging, molecular imaging, metabolic imaging and pathologic imaging.

A unique advantage of the PENN biomarker development program is the ability to determine the performance characteristics of candidate biomarkers using patients and cognitively normal elderly subjects comprehensively evaluated and followed longitudinally in the PENN Memory Center. All receive standardized assessments using a protocol established by the National Alzheimer's Coordinating Center that is used for all individuals evaluated by the 32 Alzheimer's Disease Centers, all of which are funded by the National Institute on Aging. In addition, this 'Uniform Data Set' assessment protocol has increasingly been adopted by national and international collaborative studies, including the Alzheimer's Disease Neuroimaging Initiative funded by the National Institute on Aging, reflecting a recognition of the considerable advantage associated with different studies that share common assessment protocols.

\section{Biomarkers to Identify AD Pathology - Current Status}

\section{Biochemical Biomarkers: Tau and $\beta$-Amyloid in \\ Cerebrospinal Fluid}

Quantification of tau and $\beta$-amyloid $(A \beta)$ in cerebrospinal fluid (CSF) represents the earliest and most intensively studied biomarkers of AD [4-9]. Both proteins are 
Table 1. CSF biomarker diagnostic statistics - AD versus cognitively normal elderly

\begin{tabular}{|c|c|c|c|c|c|c|c|}
\hline \multirow[t]{2}{*}{ Biomarker } & \multirow{2}{*}{$\begin{array}{l}\text { Dx cutoff } \\
\mathrm{pg} / \mathrm{ml}\end{array}$} & \multicolumn{3}{|c|}{ Clinical diagnosis of $\mathrm{AD}$} & \multicolumn{3}{|c|}{ Autopsy-confirmed AD } \\
\hline & & $\begin{array}{l}\text { subjects } \\
\mathrm{n}\end{array}$ & $\begin{array}{l}\text { mean } \\
\mathrm{pg} / \mathrm{ml}\end{array}$ & $\begin{array}{l}\text { sensi- } \\
\text { tivity }\end{array}$ & $\begin{array}{l}\text { subjects } \\
\mathrm{n}\end{array}$ & $\begin{array}{l}\text { mean } \\
\mathrm{pg} / \mathrm{ml}\end{array}$ & $\begin{array}{l}\text { sensi- } \\
\text { tivity }\end{array}$ \\
\hline t-tau & 347 & 319 & 658 & $75 \%$ & 42 & 665 & $86 \%$ \\
\hline p-tau 181 & 61 & 150 & 90 & $70 \%$ & 38 & 90 & $71 \%$ \\
\hline $\mathrm{A} \beta_{42}$ & 370 & 273 & 333 & $65 \%$ & 39 & 309 & $71 \%$ \\
\hline
\end{tabular}

$\mathrm{t}$-tau $=$ Total tau; $\mathrm{p}$-tau $=$ phosphor-tau; $\mathrm{A} \beta_{42}=42$-amino-acid fragment of $\mathrm{A} \beta$. directly linked to the 2 hallmark pathologic lesions of $\mathrm{AD}$; neuritic plaques ( $\beta$-amyloid) and neurofibrillary tangles (tau). Approximately $80 \%$ of patients who meet clinical criteria for AD have increased levels of CSF tau [9]. Autopsy studies confirmed this association and validated the relationship between high levels of CSF tau and a pathologic diagnosis of $\mathrm{AD}$ (table 1) [7].

For reasons that remain unclear, the absolute level of CSF tau in patients with AD does not correlate with the severity of the cognitive impairment or the duration of the dementia. And while it remains unknown how early in the pathological process this finding can be detected, there is general agreement that the levels of CSF tau are elevated during the prodromal stage of mild cognitive impairment (MCI) [10-13].

The development of specific phosphate-dependent tau antibodies raised the possibility that $\mathrm{AD}$ could be uniquely identified by quantifying tau phosphorylated at one of several locations (threonine 181, serine 199 or threonine 231). While elevated levels of phosphor-tau 181 may be slightly better at distinguishing AD from other late-life dementias, measurement of total tau (t-tau) appears to be best for distinguishing patients with $\mathrm{AD}$ from cognitively normal individuals. However, while elevated levels of CSF t-tau in the appropriate clinical setting (for example in the absence of acute stroke, head trauma or prion disease) support a diagnosis of $\mathrm{AD}$, failure to find elevated CSF t-tau simply reduces, but does not eliminate, the likelihood of AD pathology. Interestingly, in other neurodegenerative diseases characterized by tau pathology, such as Pick's disease, progressive supranuclear palsy and corticobasal degeneration, CSF tau levels are either normal or only slightly elevated.

Neuritic plaques associated with $\mathrm{AD}$ contain $\beta$-pleated sheets of amyloid. The 42 -amino-acid fragment of $A \beta$ $\left(A \beta_{42}\right)$ is especially prone to fibrillization and disproportionally accumulates in these extracellular lesions. Nu- merous studies have documented reduced levels of $A \beta_{42}$ in the CSF in $\mathrm{AD}$ patients $[9,14]$. However, similar reductions occur in a variety of other conditions and as a diagnostic biomarker, CSF $A \beta_{42}$ provides modest additional information beyond that obtained from knowing the CSF t-tau level [7].

\section{Regional Brain Atrophy - Detecting Disease-Related Patterns of Neuron Death}

The loss of brain volume is one of the earliest consequences of neuron death. When extreme, it can be distinguished from age-related changes and reliably detected by simple visual inspection of an MRI or CT scan. However, the key to differentiating between different neurodegenerative dementing illnesses lies in the identification of disease-related patterns of atrophy that occur before the process becomes widespread.

It has long been appreciated that AD produces regionally specific neurodegeneration, starting in the hippocampus and the entorhinal cortex [15-18]. Using standardized qualitative visual rating scales, it is possible for experienced clinicians to detect this change [19]. While helpful in supporting a diagnosis of $\mathrm{AD}$, this approach is confounded by the presence of atrophy due to other pathological processes and the generalized atrophy that occurs as part of normal aging [20,21]. In addition, the subjective nature of this approach and the experience needed to execute it reliably limit its use in routine clinical care.

Semiautomated techniques for quantitative measurements of hippocampal volume have been developed and shown to work when implemented in a clinical research setting. However, they have not been assessed in routine clinic environments. In addition, the diagnostic predictive value of hippocampal atrophy alone is limited by the large measurement overlap between normal age-related changes and changes that are disease related (fig. 1). 


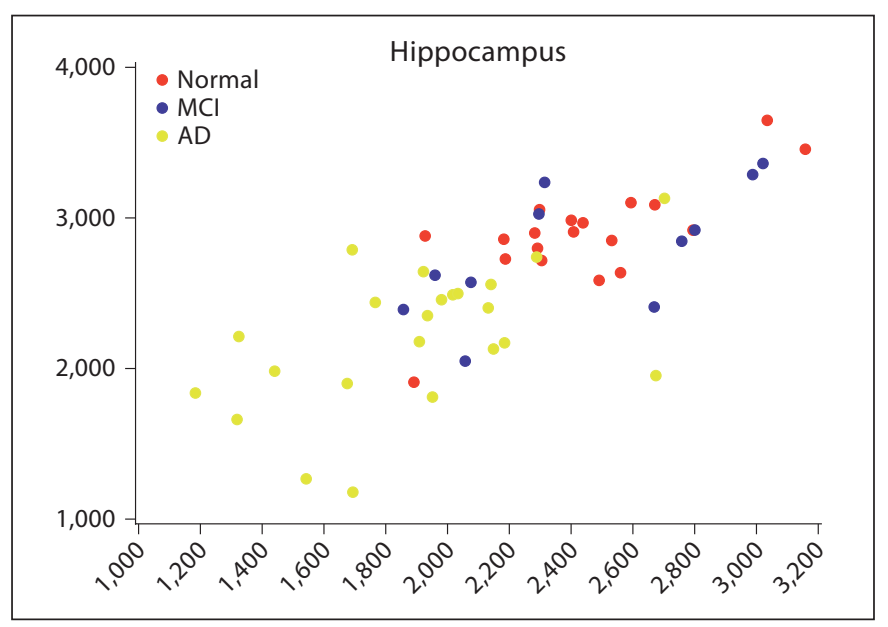

Fig. 1. Hippocampus volume in 3 diagnostic groups.

To achieve high diagnostic accuracy at the individual patient level, MRI atrophy pattern measurements must provide an almost complete separation between the disease and nondisease groups. To achieve this we have developed an atlas-based labeling and parcellation method that allows the measurement of a large number of anatomically defined areas, providing a comprehensive regional pattern of brain atrophy [22]. Once the skull has been stripped from the image, the volumes of each anatomically defined region can be determined using an automated method and are then compared to age- and gender-specific normal volumes to identify diagnostically informative differences (fig. 2).

An advantage to the measurement of multiple anatomically specific brain volumes is the recognition that structures other than the hippocampus and entorhinal cortex are affected by AD neurodegeneration. Examples include the amygdala, superior temporal sulcus, cingulate gyrus, temporal-parietal regions and the frontal lobe [23]. This provides the potential to increase the diagnostic power of MRI-derived atrophy measurements by increasing the number of anatomically defined regions assessed.

An additional advantage to this method is the ability to coregister the images with other structural images to obtain measures of the regional distribution of the signal of interest in those other images. For example, protein aggregation and amyloid deposition within each of the anatomical regions assessed can be obtained by coregistration of the MRI $T_{1} \rho$ and amyloid ligand SPECT images from the same subject.
The approach we have taken to accomplish this goal uses computer-based brain image analysis and pattern recognition to develop highly automated MRI-based methods that can determine volumes in a broad array of anatomically defined regions vulnerable to $\mathrm{AD}$ pathology. In a recent preliminary evaluation of 14 anatomical regions we validated the ability of this approach to correctly distinguish $\mathrm{AD}$ from control subjects and from individuals with mild cognitive impairment.

\section{MRI $T_{1} \rho$ Detection of Abnormal Protein Aggregation}

Although very high-resolution MRI can be used to image neuritic plaques in tissue specimens [24], it is currently not possible to accomplish this in a clinical setting. However, by modifying existing clinical MRI acquisition protocols to incorporate measures of $\mathrm{T}_{1} \rho$ relaxation time, it is possible to quantify the accumulation of abnormal protein aggregation in anatomically defined brain regions $[25,26]$. This opens the possibility of developing an MRI-based molecular imaging biomarker of AD-related pathology that could be used in a community healthcare setting.

In an initial test of the potential of this approach, MRI $\mathrm{T}_{1} \rho$ values were determined for $5 \mathrm{AD}, 2 \mathrm{MCI}$ and 7 controls subjects. $\mathrm{T}_{1} \rho$ values from pixels located in the temporal lobe regions as defined by the regional cortical atrophy maps were averaged for gray and white matter pixels separately. Average $\mathrm{T}_{1} \rho$ was significantly higher $(\mathrm{p}=$ 0.0235) for the AD cohort in the gray matter of both left and right temporal lobes compared to $\mathrm{MCI}$ and controls (fig. 3).

When combined with regional cortical atrophy and CSF tau measurements, MRI $\mathrm{T}_{1} \rho$ could significantly improve the certainty that $\mathrm{AD}$-related pathology is present.

\section{Using PET and SPECT to Identify AD Pathology}

$\mathrm{AD}$ is associated with a metabolic impairment that often has a 'typical' regional pattern, initially affecting the parietal and temporal lobes as well as the posterior cingulate before progressing to the frontal lobes and other brain structures. In general, the cerebellum, lower brainstem and spinal cord are spared. These metabolic changes can be visualized using $\left[{ }^{18} \mathrm{~F}\right]$-2-fluoro-deoxy-D-glucose PET (FDG-PET) and the pattern of impairment is often helpful in distinguishing $\mathrm{AD}$ from other causes of late-life dementia $[27,28]$. Alternative methods of viewing the images, such as stereotactic surface projection, make it possible for a physician not formerly trained in neuroradiology to reliably interpret the studies [29]. Nev- 
Fig. 2. Volumetric measurements using high-dimensional template warping (HAMMETR technique).
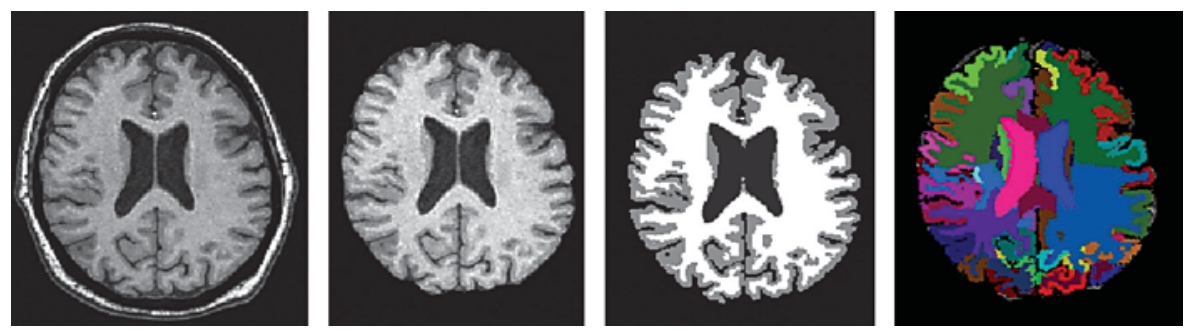

ertheless, the final interpretation of the image remains a qualitative judgment as to whether the pattern and intensity of regional FDG activity supports a diagnosis of AD.

More recently, radioactive ligands have been developed to visualize aggregates of $A \beta$. The benzothiazolederived $\left[{ }^{11} \mathrm{C}\right]$-Pittsburgh compound B PET (PIB-PET) ligand is an early example. It is retained in the areas of the brain known to harbor amyloid plaques and increased levels can be demonstrated in some individuals with MCI. However, abnormal retention can also occur in individuals with normal cognition, and longitudinal studies to date have not clearly demonstrated progressively increased retention of PIB in patients with AD [30-34]. In addition, the 20 -min half-life of ${ }^{11} \mathrm{C}$ limits its clinical application.

More recently, ${ }^{18} \mathrm{~F}$ (SB-13) stilbene derivatives have been developed as potential PET amyloid ligands [35]. ${ }^{18} \mathrm{~F}$ ligands are of particular benefit because the longer halflife of the isotope makes it possible to use them in a clinical setting. Nevertheless, while the successful development of an $A \beta$ amyloid PET ligand would have both research and clinical benefits, the cost and limited availability of PET scanners will constrain their widespread use.

\section{Single Photon Emission Computerized Tomography}

Routine SPECT images provide a qualitative visual map of cerebral perfusion and have been used for many years in the evaluation of patients with cognitive impairment as a surrogate marker of impaired neuronal metabolism. While they provide some clinically useful information [36], the results are often not definitive and, in general, do not provide information about the specific pathology responsible for the reduced cerebral perfusion.

Biomarkers for Early Detection of Alzheimer Pathology

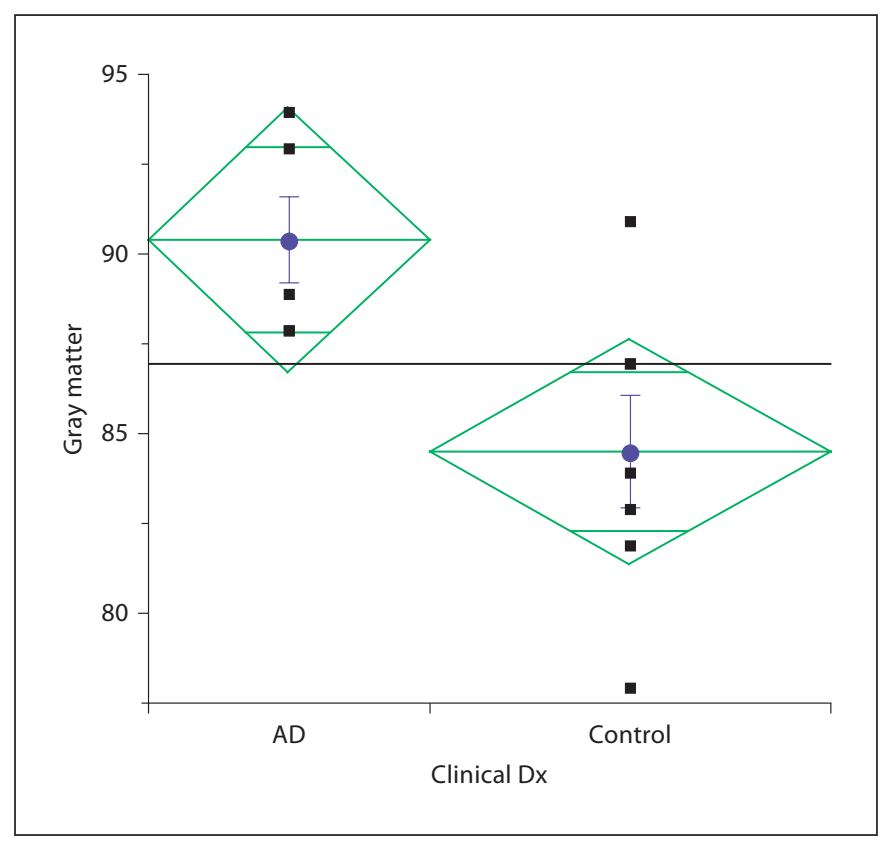

Fig. 3. Gray matter $M R I T_{1} \rho$ in $A D$ and control subjects.

More recently, SPECT-compatible amyloid ligands have been developed. This approach offers considerable advantage over the use of PET scans, as the imaging hardware is considerably cheaper and much more widely available. Our initial studies used an ${ }^{125} \mathrm{I}$ imidazol derivative (IMPY) synthesized in the radiopharmaceutical chemistry section of PENN's Department of Radiology. In postmortem studies, IMPY bound to $A \beta$ amyloid plaques in postmortem brain tissue from patients with a pathological diagnosis of AD [37]. Subsequent studies in humans using a ${ }^{123}$ I version of the compound documented that this first-generation SPECT amyloid ligand could distinguish $\mathrm{AD}$ patients from elderly control subjects (table 2).

Neurosignals 2008;16:11-18 


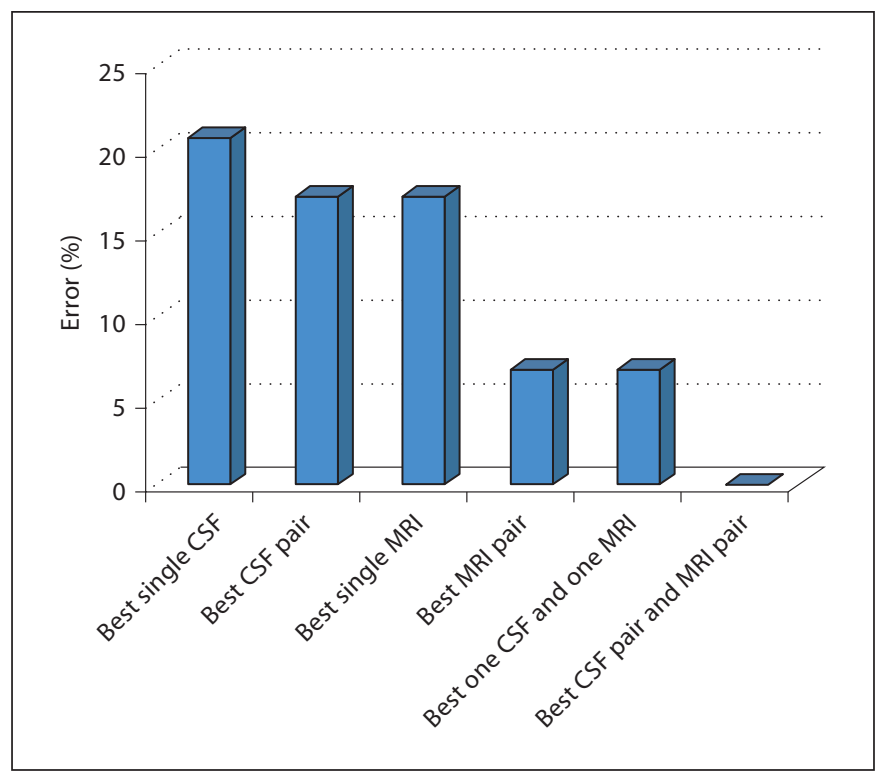

Fig. 4. Improvement in biomarker performance with data fusion.

We are now evaluating a second-generation compound (AV-57) that appears to have superior amyloid binding properties.

\section{Data Fusion - Combining Biomarkers for Better Diagnostic Certainty}

While each of the candidate biomarkers has the potential to identify the presence of AD-related neurodegenerative pathology, it is unlikely any single one (imaging or biochemical) will have adequate positive or negative predictive power to be sufficient as the only test needed to make a definitive diagnosis in an individual patient. More likely, it will be necessary to select a number of biomarker tests that in combination will be most informative for the clinical question asked. Thus, developing methods to select and combine data from different biomarkers (data fusion) to generate a diagnostic decision with the highest predictive value represents an important component of the PENN biomarker development program.

Since the biomarkers differ from each other in fundamental ways (that is, brain volumes vs. protein concentrations vs. ligand retention ratios), the two main tasks for data fusion are to determine the type of preprocessing that must be done on the results from each biomarker and how to combine the postprocessed information to yield the best overall diagnostic performance.
Table 2. IMPY uptake ratios (cortex to striatum)

\begin{tabular}{llll}
\hline Brain area & $\mathrm{AD}(\mathrm{n}=5)$ & Controls $(\mathrm{n}=4)$ & $\mathrm{p}$ value \\
\hline Right frontal & $1.20(0.15)$ & $0.86(0.09)$ & 0.01 \\
Left frontal & $1.31(0.21)$ & $0.87(0.09)$ & 0.02 \\
Right parietal & $1.18(0.22)$ & $0.82(0.10)$ & 0.04 \\
Left parietal & $1.20(0.19)$ & $0.79(0.05)$ & 0.01 \\
Right temporal & $1.22(0.20)$ & $0.88(0.13)$ & 0.05 \\
Left temporal & $1.22(0.19)$ & $0.88(0.14)$ & 0.04 \\
All areas & $1.22(1.18)$ & $0.85(0.09)$ & 0.03 \\
\hline
\end{tabular}

Data are presented as means with SD in parentheses.

Using data from $14 \mathrm{AD}$ and 15 control subjects, we recently evaluated 3 standard supervised learning algorithms: logistic regression (LogReg), support vector machine (SVM) and linear discriminate analysis (LDA) to test the diagnostic performance before and after combining the values for CSF t-tau and $A \beta_{42}$ with the volumes from 24 anatomically defined regions obtained from the MRIs. The goal was to determine if (1) combining multiple CSF biomarkers yields better diagnosis than individual biochemical biomarkers, (2) combining multiple MRI features yields better diagnosis than individual MRI features, and (3) combining CSF and MRI biomarkers can further improve the diagnostic accuracy. The results support the advantage of a data fusion strategy in that combining information from different biomarkers always reduced the diagnostic error rate compared to depending upon information from a single biomarker.

Combining one CSF and one MRI biomarker each produces a lower error (6.9\%) than any single CSF or MRI biomarker, and combining the best CSF pair and MRI pair led to the best diagnostic prediction (fig. 4).

\section{Conclusion}

The development of biomarkers to detect specific types of neuropathology that cause dementia and, most importantly, those associated with AD-related MCI will allow clinicians in the community to successfully identify patients and initiate disease-modifying treatment at the earliest recognizable stage of disease. And it is precisely at this stage when the clinical diagnosis is most difficult. It is also likely that overall treatment effectiveness will be maximized when the treatment is started as early in the pathological process as possible. 
Given the prevalence of $\mathrm{AD}$, it is likely that most patients will be diagnosed and selected for treatment on the basis of evaluations done by community-based physicians. Thus, the overarching goal of the PENN biomarker development program is to provide tools communitybased physicians can use to safely and reliably accomplish that task.

\section{Acknowledgements}

We are indebted to the patients and families whose dedication and partnership make this work possible. Support for research summarized here comes from the NIH (AG10124), the Pennsylvania Department of Health (SAP4100027296), the James Previti Family Fund and Marian S. Ware.

\section{References}

1 Ferri CP, Prince M, Brayne C, Brodaty H, Fratiglioni L, Ganguli M, Hall K, Hasegawa $\mathrm{K}$, Hendrie H, Huang Y, Jorm A, Mathers C, Menezes PR, Rimmer E, Scazufca M; Alzheimer's Disease International: Global prevalence of dementia: a Delphi consensus study. Lancet 2005;366:2112-2117.

2 Shaw LM, Korecka M, Clark CM, Lee VM, Trojanowski JQ: Biomarkers of neurodegeneration for diagnosis and monitoring therapeutics. Nat Rev Drug Discov 2007;6:295303.

- 3 Hebert LE, Scherr PA, Bienias JL, Bennett DA, Evans DA: Alzheimer disease in the US population: prevalence estimates using the 2000 census. Arch Neurol 2003;60:11191122 .

-4 Blennow K: Cerebrospinal fluid protein biomarkers for Alzheimer's disease. NeuroRx 2004;1:213-225.

5 Blennow K, Hampel H: CSF markers for incipient Alzheimer's disease. Lancet Neuro 2003;2:605-613.

6 Clark CM, Karlawish JH: Alzheimer disease: current concepts and emerging diagnostic and therapeutic strategies. Ann Intern Med 2003;138:400-410.

7 Clark CM, Xie S, Chittams J, Ewbank D, Peskind E, Galasko D, Morris JC, McKeel DW Jr., Farlow M, Weitlauf SL, Quinn J, Kaye J, Knopman D, Arai H, Doody RS, DeCarli C, Leight S, Lee VM, Trojanowski JQ: Cerebrospinal fluid tau and $\beta$-amyloid: how well do these biomarkers reflect autopsyconfirmed dementia diagnoses? Arch Neurol 2003;60:1696-1702.

-8 Clark CM, Pratico D, Shaw LM, Leight S, Xie SX, Gu A, Lee VMY, Trojanowski JQ: Commentary on 'Optimal design of clinical trials for drugs designed to slow the course of Alzheimer's disease'. Biochemical biomarkers of late-life dementia. Alzheimers Dement 2006 2:287-293.

-9 Blennow K, Vanmechelen E, Hampel H: CSF total tau, $A \beta 42$ and phosphorylated tau protein as biomarkers for Alzheimer's disease. Mol Neurobiol 2001;24:87-97.
Andreasen N, Vanmechelen E, Vanderstichele H, Davidsson P, Blennow K: Cerebrospinal fluid levels of total-tau, phosphotau and $A \beta 42$ predicts development of Alzheimer's disease in patients with mild cognitive impairment. Acta Neurol Scand 2003;179(suppl):47-51.

11 Arai $\mathrm{H}$, Ishiguro K, Ohno H, Moriyama M, Itoh N, Okamura N, Matsui T, Morikawa Y, Horikawa E, Kohno H, Sasaki H, Imahori K: CSF phosphorylated tau protein and mild cognitive impairment: a prospective study. Exp Neurol 2000;166:201-203.

12 Buerger K, Teipel SJ, Zinkowski R, Blennow K, Arai H, Engel R, Hofmann-Kiefer K, McCulloch C, Ptok U, Heun R, Andreasen N, DeBernardis J, Kerkman D, Moeller H, Davies $\mathrm{P}$, Hampel $\mathrm{H}$ : CSF tau protein phosphorylated at threonine 231 correlates with cognitive decline in MCI subjects. Neurology 2002;59:627-629.

13 Hansson O, Zetterberg H, Buchhave P, Londos E, Blennow K, Minthon L: Association between CSF biomarkers and incipient Alzheimer's disease in patients with mild cognitive impairment: a follow-up study. Lancet Neurol 2006;5:228-234.

14 Galasko D: Biological markers and the treatment of Alzheimer's disease. J Mol Neurosci 2001;17:119-125.

15 Csernansky JG, Wang L, Joshi S, Miller JP, Gado M, Kido D, McKeel D, Morris JC, Miller MI: Early DAT is distinguished from aging by high-dimensional mapping of the hippocampus. Neurology 2000;55:1636-1643.

16 Dickerson BC, Goncharova I, Sullivan MP, Forchetti C, Wilson RS, Bennett DA, Beckett LA, deToledo-Morrell L: MRI-derived entorhinal and hippocampal atrophy in incipient and very mild Alzheimer's disease. Neurobiol Aging 2001;22:747-754.

17 Rosen AC, Prull MW, Gabrieli JD, Stoub T, O’Hara R, Friedman L, Yesavage JA, deToledo-Morrell L: Differential associations between entorhinal and hippocampal volumes and memory performance in older adults. Behav Neurosci 2003;117:1150-1160.
8 Stoub TR, Bulgakova M, Leurgans S, Bennett DA, Fleischman D, Turner DA, deToledoMorrell L: MRI predictors of risk of incident Alzheimer disease: a longitudinal study. Neurology 2005;64:1520-1524.

19 Scheltens P, Pasquier F, Weerts JG, Barkhof F, Leys D: Qualitative assessment of cerebral atrophy on MRI: inter- and intra-observer reproducibility in dementia and normal aging. Eur Neurol 1997;37:95-99.

20 Resnick SM, Goldszal A, Davatzikos C, Golski S, Kraut MA, Metter EJ, Bryan RN, Zonderman AB: One-year age changes in MRI brain volumes in older adults. Cereb Cortex 2000;10:464-472.

21 Sullivan EV, Pfefferbaum A, Adalsteinsson E, Swan GE, Carmelli D: Differential rates of regional brain change in callosal and ventricular size: a 4-year longitudinal MRI study of elderly men. Cereb Cortex 2002;12:438445.

22 Liu T, Shen DG, Davatzikos C: Deformable registration of cortical structures via hybrid volumetric and surface warping. Neuroimage 2004;22:1790-1801.

23 Chetelat G: Early diagnosis of Alzheimer's disease: contribution of structural neuroimaging. Neuroimage 2003;18:525-541.

24 Benveniste H, Einstein G, Kim KR, Hulette C, Johnson GA: Detection of neuritic plaques in Alzheimer's disease by magnetic resonance microscopy. Proc Natl Acad Sci USA 1999;96:14079-14084.

25 Borthakur A, Gur T, Wheaton AJ, Corbo M, Trojanowski JQ, Lee VM, Reddy R: In vivo measurement of plaque burden in a mouse model of Alzheimer's disease. J Magn Reson Imaging 2006;24:1011-1017.

26 Borthakur A, Wheaton AJ, Gougoutas AJ, Akella SV, Regatte RR, Charagundla SR, Reddy R: In vivo measurement of $\mathrm{T}_{1} \rho$ dispersion in the human brain at 1.5 tesla. J Magn Reson Imaging 2004;19:403-409.

27 Heidebrink JL, Barbas NR, Turner RS, Clark CM, Jagust WJ, Arnold SE, DeCarli CS, Koeppe RA, Higdon R, Foster NL: FDG-PET improves differential diagnosis of dementia when clinical history and examination are ambiguous. Neurobiol Aging 2004;25:370371. 
-28 Silverman DH, Small GW, Chang CY, Lu CS, Kung de Aburto MA, Chen W, Czernin J, Rapoport SI, Pietrini P, Alexander GE, Schapiro MB, Jagust WJ, Hoffman JM, WelshBohmer KA, Alavi A, Clark CM, Salmon E, de Leon MJ, Mielke R, Cummings JL, Kowell AP, Gambhir SS, Hoh CK, Phelps ME: Positron emission tomography in evaluation of dementia: regional brain metabolism and long-term outcome. JAMA 2001;286:21202127.

29 Foster NL, Barbas NR, Heidebrink JL, Turner RS, Clark CM, Jagust WJ, Arnold SE, DeCarli CS, Koeppe RA, Higdon R: Adding FDG-PET to clinical history and examination improves the accuracy of dementia diagnosis. Neurobiol Aging 2004;25:372.

- 30 Archer HA, Edison P, Brooks DJ, Barnes J, Frost C, Yeatman T, Fox NC, Rossor MN: Amyloid load and cerebral atrophy in Alzheimer's disease: an 11C-PIB positron emission tomography study. Ann Neurol 2006; 60:145-147.
1 Edison P, Archer HA, Hinz R, Hammers A, Pavese N, Tai YF, Hotton G, Cutler D, Fox N, Kennedy A, Rossor M, Brooks DJ: Amyloid, hypometabolism, and cognition in Alzheimer disease. An [11C]PIB and [18F]FDG PET study. Neurology 2007;68:501-508.

32 Engler H, Forsberg A, Almkvist O, Blomquist G, Larsson E, Savitcheva I, Wall A, Ringheim A, Langstrom B, Nordberg A: Two-year follow-up of amyloid deposition in patients with Alzheimer's disease. Brain 2006;129: 2856-2866.

33 Kemppainen NM, Aalto S, Wilson IA, Nagren K, Helin S, Bruck A, Oikonen V, Kailajarvi M, Scheinin M, Viitanen M, Parkkola $\mathrm{R}$, Rinne JO: Voxel-based analysis of PET amyloid ligand [11C]PIB uptake in Alzheimer disease. Neurology 2006;67:1575-1580.
4 Mintun MA, Larossa GN, Sheline YI, Dence CS, Lee SY, Mach RH, Klunk WE, Mathis CA, DeKosky ST, Morris JC: [11C]PIB in a nondemented population: potential antecedent marker of Alzheimer disease. Neurology 2006;67:446-452.

35 Zhang W, Oya S, Kung MP, Hou C, Maier DL, Kung HF: F-18 Polyethyleneglycol stilbenes as PET imaging agents targeting $A \beta$ aggregates in the brain. Nucl Med Biol 2005; 32:799-809.

36 Jagust W, Thisted R, Devous MD Sr, Van Heertum R, Mayberg H, Jobst K, Smith AD, Borys N: SPECT perfusion imaging in the diagnosis of Alzheimer's disease: a clinicalpathologic study. Neurology 2001;56:950956.

37 Kung MP, Hou C, Zhuang ZP, Skovronsky D, Kung HF: Binding of two potential imaging agents targeting amyloid plaques in postmortem brain tissues of patients with Alzheimer's disease. Brain Res 2004;1025:98105. 